\title{
Methylation of Glutathione-S-Transferase P1 Promotor in Egyptian Females with Breast Cancer
}

\author{
Thanaa Fathy Moghazy ${ }^{1}$, Hoda Aly Elattar', Mona Kamal Eldeeb ${ }^{1 *}$, Radwa \\ Mohammed Rashad ${ }^{1}$, Ayman Mohamed Farouk ${ }^{2}$, Assmaa Mostafa Farrag ${ }^{1}$
}

\begin{abstract}
Background: Breast cancer (BC) is the second most common cancer after the lung cancer worldwide and number one killing cancer in Egyptian females . It is a multifactorial disease driven by different environmental, hormonal, genetic and epigenetic factors. Epigenetic alterations have been studied in cancer breast. Role of GSTP1 promotor methylation in breast cancer has been studied in different ethnic groups. Objectives: Current study aimed at studying the methylation status of the promotor region of glutathione-S-transferase P1 in breast ductal carcinoma of a cohort group of Egyptian females and its correlations with histopathological and prognostic parameters. Methods: Control group included 15 fresh normal breast tissues taken from BC female patients after leaving a clearly defined safety margin and a Patient group included confirmed 35 fresh breast ductal carcinoma tissue biopsies taken from female patients postoperatively. To all patients clinical examination, radiological examination (plain X-ray chest and or CT scan, ultrasonography of abdomen and pelvis were done), in addition to histopathological examination, typing, grading and staging of tumour, hormonal receptors status and molecular typing of breast mass. GSTP1 methylation status was evaluated using methyl specific polymerase chain reaction. Results: Statistical significant increase was found in methylation status of GSTP1 promotor gene in BC cases than that in control group, $(60 \%$ of patients samples had methylated GSTP1 promotor vs only $6.7 \%$ of controls) ( $p=>0.001)$. No association was found between GSTP1 promotor methylation status and the poor prognostic factors neither with hormonal profile nor molecular type. However, GSTP1 promotor methylation were two times higher in postmenopausal than premenopausal cases and three times higher in late grade (III). Also GSTP1 promotor methylation was 2.4 times higher in Her2 positive cases than either ER or PR positive cases. Conclusion: Glutathione-S-Transferase P1 Promotor methylation plays a role in breast cancer development.
\end{abstract}

Keywords: GSTP1 promotor- epigenetics- breast cancer

Asian Pac J Cancer Prev, 20 (8), 2523-2530

\section{Introduction}

Breast cancer $(\mathrm{BC})$ is the second most prevalent malignancy among women worldwide after lung cancer (Bray et al., 2018). In Egypt, BC is the most common cancer among women (incidence rate $32 \%$ ) as published in 2014 and it is considered number one killing cancer in Egyptian females (Ibrahim et al., 2014). Breast cancer is a heterogeneous disease that is challenging to characterize and treat (Byler et al., 2014). It is a complex multifactorial disease that can be driven by different environmental, hormonal, genetic and epigenetic factors which included several studied genes in cancer breast (Lo et al., 2008).

The Pi-class glutathione-S-transferase (GSTP1) belongs to Glutathione-S-transferases (GSTs) family. GSTP1 is considered a phase II metabolic enzyme that detoxifies reactive electrophilic intermediates, thus playing an important role in protecting cells from cytotoxic, carcinogenic agents (Wu et al., 2016) and conjugation of hormones as estrogen (Schnekenburger at al., 2014).

Variable genetic modifications have been found to affect the function of GSTP1 gene as mutations and polymorphism. In addition different epigenetic modifications in GSTP1 have been identified which include DNA methylation, histone modification, nucleosome positioning, chromosomal looping and non coding RNAs (Fazzari and Greally , 2004). Epigenetic silencing of GSTP1 gene expression which is induced by promotor methylation has been found to be implicated in the pathogenesis of different types of cancers (Allocati et al., 2018).

It was found that methylation of the promotor regions of several genes, including known tumor suppressor genes (as GSTP1 and Breast cancer type 1 (BRCA1) and Ras-association domain family $(R A S S F)$, results 
in the subsequent failure to express their functional proteins as DNA methylation may impede the binding of transcriptional regulators to the gene (Jin et al., 2012; Sheng et al., 2017). Consequently, DNA methylation may represent an early and fundamental step in the pathway by which normal tissue undergoes neoplastic transformation (Wajed et al., 2001).

Aberrant methylation of the GSTP1 has been reported to occur in different types of cancer including those of liver (Huang et al., 2011), prostate (Yang and Park, 2012), hematological malignancies (Karius et al., 2011) and breast (Brooks et al., 2009; Pongtheerat et al., 2011).

The role of GSTP1 promotor methylation in cancer breast has been studied in different ethnic groups. However, the data concerning its role in breast cancer in Egyptian population is still insufficient. The present work aimed at studying the methylation status to the promotor region of glutathione-S-transferase $\mathrm{P} 1$ in breast ductal carcinoma of Egyptian females. The presence of methylation was also correlated with the histopathological and prognostic parameters.

\section{Material and Methods}

\section{Materials}

After the approval of the Ethics Committee of the Medical Research Institute, Alexandria University and taking informed consents from the patients, this study was conducted on 35 female patients with histopathologically confirmed breast ductal carcinoma. The breast tissue biopsies were taken from these patients during operation from both cancer and normal breast tissues. The biopsies were divided into 2 groups Control group included 15 fresh biopsies of normal breast tissue taken after leaving a clearly defined safety margin and Patients group included 35 fresh biopsies of histopathologically proved breast ductal carcinomas tissue biopsies. All female patients were chosen non-pregnant and were not using contraceptive hormonal methods. Patients with previous cancer history , other malignancy and metastasized cancer from other organs were excluded from the study.

\section{Methods}

Detailed history including age, menstrual history and parity was taken. Thorough clinical examination, radiological examination (plain X-ray for the chest and/or CT scan, ultrasonography of abdomen and pelvis and bone scan; if needed). In addition histopathological examination of breast tissue including typing, grading and staging of tumor and hormonal receptors status (ER, PR and HER2) were done (Onitilo et al., 2009)
Detection of GSTP1 methylation status was done for both groups as follows:

1- Genomic DNA extraction was done using QIAamp DNA Mini Kit (Qiagen, Germany. Cat. No : 51304) according to the manufacturer's instructions (Kalmár et al., 2015).

2- The extracted DNA was assessed for integrity by agarose gel electrophoresis as well as purity and concentration using Thermo Scientific NanoDrop ${ }^{\mathrm{TM}}$ 1000 Spectrophotometer (Thermo Fisher Scientific, Wilmington, Delaware, USA) (Sambrook et al., 2006; Desjardins et al., 2010).

3- The methylation status of a DNA sequence was determined using bisulfite conversion. After bisulfite treatment of genomic DNA. The treated DNA was then subjected to Methyl Specific PCR (Holmes et al., 2014; Alnaes et al., 2015).

4- The methylation status was assessed using two sets of Methyl specific primers (MSP) primers complementary to the unmethylated and methylated sequences. Each of the PCR primers covered more than one $\mathrm{CpG}$, and the resulting PCR products were then read against comparable ladder (50 bp- $1000 \mathrm{bp}$ ) using gel electrophoresis (Alnaes et al. , 2015). Methylated GSTP1 showed bands at (91 bp) and umethylated GSTP1 showed bands at (97 bp).

\section{Statistical analysis}

Data were analyzed using IBM SPSS software, Normality of the results was assessed using "SPSS Levene's Test". Then Chi-square test was used for categorical variables, to compare between different groups, Fisher's Exact or Monte Carlo correction for chi-square when more than $20 \%$ of the cells have expected count less than 5 . For normally distributed tests we used Student t-test was used for quantitative variables, to compare between two studied groups, as for abnormally distributed quantitative variables we used Mann Whitney test to compare between two studied groups and at last Odd ratio (OR) was used to calculate the ratio of the odds and $95 \%$ Confidence Interval (C.I.) of an event occurring in a risky group to the odds of it occurring in the nonrisky group.

\section{Results}

Breast cancer biopsies showed statistical significant increase in the methylation status of GSTP1 promotor region than that of normal control biopsies with $\mathrm{p}=<0.001$ and $\mathrm{OR}=21.0$ which denotes that the odds of finding the GSTP1 promotor region methylated in breast cancer tissues was 21 times the odds of finding control tissues

Table 1. Statistical Analysis of the Frequency of GSTP1 Promoter Methylation Status in the Studied Groups

\begin{tabular}{|c|c|c|c|c|c|c|c|}
\hline & \multicolumn{2}{|c|}{ Cases (Group2) $(\mathrm{n}=35)$} & \multicolumn{2}{|c|}{ Control ${ }^{\circledR}($ Group 1$)(\mathrm{n}=15)$} & \multirow[t]{2}{*}{ OR } & \multicolumn{2}{|c|}{$95 \% \mathrm{CI}$} \\
\hline & No. & $\%$ & No. & $\%$ & & LL & UL \\
\hline \multicolumn{8}{|l|}{ Results } \\
\hline Unmethylated $\AA$ & 14 & 40 & 14 & 93.3 & $21.0^{*}$ & 2.474 & 178.22 \\
\hline Methylated & 21 & 60 & 1 & 6.7 & & & \\
\hline$\chi^{2}(\mathrm{p})$ & \multicolumn{4}{|c|}{$12.121 *(<0.001 *)$} & & & \\
\hline
\end{tabular}


DOI:10.31557/APJCP.2019.20.8.2523

Methylation of GSTP1 Egyptian Females

Table 2. Continue Relation between Methylation Status of GSTP1 Promoter Region and Different Parameters in the Patients Group

\begin{tabular}{|c|c|c|c|c|c|c|c|c|c|}
\hline & \multicolumn{2}{|c|}{$\begin{array}{l}\text { Un-methylated } \\
\qquad(\mathrm{n}=14)\end{array}$} & \multicolumn{2}{|c|}{$\begin{array}{l}\text { Methylated } \\
(\mathrm{n}=21)\end{array}$} & \multirow[t]{2}{*}{ Test of sig. } & \multirow[t]{2}{*}{$P$} & \multirow[t]{2}{*}{ OR } & \multicolumn{2}{|c|}{$95 \% \mathrm{CI}$} \\
\hline & No. & $\%$ & No. & $\%$ & & & & LL & ML \\
\hline \multicolumn{10}{|l|}{ Age (years) } \\
\hline$>50(\mathrm{n}=13)$ & 7 & 53.9 & 6 & 46.1 & $\chi^{2}=1.652$ & 0.199 & & & \\
\hline$\geq 50(\mathrm{n}=22)$ & 7 & 31.8 & 15 & 68.2 & & & 2.5 & 0.609 & 10.261 \\
\hline $30-40(n=4)$ & 1 & 25.0 & 3 & 75.0 & $\chi^{2}=3.461$ & $\mathrm{MC}_{\mathrm{p}}=0.151$ & & & \\
\hline$>40-49(\mathrm{n}=9)$ & 6 & 66.7 & 3 & 33.3 & & & 0.167 & 0.012 & 2.368 \\
\hline$\geq 50(\mathrm{n}=22)$ & 7 & 31.8 & 15 & 68.2 & & & 0.714 & 0.063 & 8.15 \\
\hline Mean $\pm \mathrm{SD}$ & \multicolumn{2}{|c|}{$51.71 \pm 8.53$} & \multicolumn{2}{|c|}{$52.86 \pm 9.12$} & $\mathrm{t}=0.372$ & 0.712 & 1.015 & 0.939 & 1.098 \\
\hline \multicolumn{10}{|l|}{ Menstrual history } \\
\hline Premenopausal $(n=16)$ & 8 & 50 & 8 & 50 & 1.228 & $\mathrm{FEp}=0.317$ & 2.167 & 0.547 & 8.586 \\
\hline Postmenopausal ( $\mathrm{n}=19)$ & 6 & 31.6 & 13 & 68.4 & & & & & \\
\hline \multicolumn{10}{|l|}{ Parity } \\
\hline No $(n=5)$ & 2 & 40 & 3 & 60 & 0.00 & $\mathrm{FE}_{\mathrm{p}}=1$ & 1 & 0.145 & 6.907 \\
\hline Multi $(\mathrm{n}=30)$ & 12 & 40 & 18 & 60 & & & & & \\
\hline \multicolumn{10}{|l|}{ Tumor } \\
\hline $\mathrm{T} 1(\mathrm{n}=10)$ & 3 & 30 & 7 & 70 & 0.663 & $\mathrm{MC}_{\mathrm{p}}=0.826$ & & & \\
\hline $\mathrm{T} 2(\mathrm{n}=14)$ & 6 & 42.9 & 8 & 57.1 & & & 0.571 & 0.103 & 3.183 \\
\hline $\mathrm{T} 3(\mathrm{n}=11)$ & 5 & 45.5 & 6 & 54.5 & & & 0.514 & 0.085 & 3.109 \\
\hline \multicolumn{10}{|l|}{$\mathrm{LN}$} \\
\hline Negative $(\mathrm{n}=9)$ & 6 & 66.7 & 3 & 33.3 & 3.59 & $\mathrm{FE}_{\mathrm{p}}=0.112$ & & & \\
\hline Positive ( $\mathrm{n}=26$ ) & 8 & 30.8 & 18 & 69.2 & & & 0.222 & 0.044 & 1.119 \\
\hline \multicolumn{10}{|l|}{ Grade } \\
\hline $\mathrm{II}(\mathrm{n}=30)$ & 13 & 43.3 & 17 & 56.7 & 0.972 & $\mathrm{FE}_{\mathrm{p}}=0.627$ & & & \\
\hline \multirow[t]{2}{*}{ III $\quad(n=5)$} & 1 & 20 & 4 & 80 & & & 3.059 & 0.304 & 30.731 \\
\hline & No. & $\%$ & No. & $\%$ & & & & LL & UL \\
\hline \multicolumn{10}{|l|}{ Stage } \\
\hline $\begin{array}{l}\text { Early stage (IIA and B) } \\
(\mathrm{n}=20)\end{array}$ & 8 & 40 & 12 & 60 & 0 & $\mathrm{FE}_{\mathrm{p}}=1$ & & & \\
\hline $\begin{array}{l}\text { Late stage (IIIA and C) } \\
(\mathrm{n}=15)\end{array}$ & 6 & 40 & 9 & 60 & & & 1 & 0.255 & 3.922 \\
\hline \multicolumn{10}{|l|}{ ER } \\
\hline Negative $(n=8)$ & 1 & 12.5 & 7 & 87.5 & 3.268 & $\mathrm{FE}_{\mathrm{p}}=0.108$ & & & \\
\hline Positive $(\mathrm{n}=27$ ) & 13 & 48.1 & 14 & 51.9 & & & 0.154 & 0.017 & 1.427 \\
\hline \multicolumn{10}{|l|}{ PR } \\
\hline Negative $(\mathrm{n}=9)$ & 1 & 11.1 & 8 & 88.9 & 4.213 & $\mathrm{FE}_{\mathrm{p}}=0.056$ & & & \\
\hline Positive $(\mathrm{n}=26$ ) & 13 & 50 & 13 & 50 & & & 0.125 & 0.014 & 1.147 \\
\hline \multicolumn{10}{|l|}{ Her2 } \\
\hline Negative $(\mathrm{n}=27)$ & 12 & 44.4 & 15 & 55.6 & 0.972 & $\mathrm{FE}_{\mathrm{p}}=0.431$ & & & \\
\hline Positive $(n=8)$ & 2 & 25 & 6 & 75 & & & 2.4 & 0.408 & 14.107 \\
\hline \multicolumn{10}{|l|}{ Molecular type } \\
\hline Triple negative $(\mathrm{n}=4)$ & 1 & 25 & 3 & 75 & 3.568 & $\mathrm{MC}_{\mathrm{p}}=0.338$ & & & \\
\hline Luminal A (n=23) & 11 & 47.8 & 12 & 52.2 & & & 0.364 & 0.033 & 4.035 \\
\hline Luminal B (n=4) & 2 & 50 & 2 & 50 & & & 0.333 & 0.017 & 6.654 \\
\hline Her 2 enriched $(n=4)$ & 0 & 0 & 4 & 100 & & & - & - & - \\
\hline
\end{tabular}

$\chi^{2}$, Chi square test; FE, Fisher Exact; MC, Monte Carlo; U, Mann Whitney test; p, p value for comparing between the two groups; *, Statistically significant at $\mathrm{p} \leq 0.05$; OR, Odds ratio;CI, Confidence interval; LL, Lower limit; UL, Upper Limit 
Table 3. Relation between Hormonal Profile and Tumors Grade in the Studied Biopsies of Patients Group

\begin{tabular}{|c|c|c|c|c|c|c|}
\hline & \multicolumn{4}{|c|}{ Grade } & \multirow[t]{4}{*}{$\chi^{2}$} & \multirow[t]{4}{*}{$\mathrm{FE}_{\mathrm{p}}$} \\
\hline & \multicolumn{2}{|c|}{ II } & \multicolumn{2}{|c|}{ III } & & \\
\hline & $(\mathrm{n}=30)$ & & $(\mathrm{n}=5)$ & & & \\
\hline & No. & $\%$ & No. & $\%$ & & \\
\hline \multicolumn{7}{|l|}{ ER } \\
\hline Negative $(n=8)$ & 4 & 13.3 & 4 & 80 & $10.802 *$ & $0.006^{*}$ \\
\hline Positive $(\mathrm{n}=27)$ & 26 & 86.7 & 1 & 20 & & \\
\hline \multicolumn{7}{|l|}{ PR } \\
\hline Negative $(n=9)$ & 5 & 16.7 & 4 & 80 & $8.999 *$ & $0.010^{*}$ \\
\hline Positive $(n=26)$ & 25 & 83.3 & 1 & 20 & & \\
\hline \multicolumn{7}{|l|}{ Her2 } \\
\hline Negative $(n=27)$ & 24 & 80 & 3 & 60 & 0.972 & 0.568 \\
\hline Positive $(n=8)$ & 6 & 20 & 2 & 40 & & \\
\hline
\end{tabular}

methylated (Table 1 ).

There was no statistical significant difference in methylation status of GSTP1 promotor region between age groups. $(\mathrm{p}=0.199)$ although females aged 50 years or older are at 2.5 times risk to develop methylation in GSTP1 promotor region than females younger than 50 years as OR was 2.5. (Table 2).

Also no significant association between the clinicopathological factors that are risky for breast cancer (menopausal state, multiparity, grade, stage and Her2) and the presence of methylation of GSTP1 promotor. However, postmenopausal ladies were two times at risk to have methylated GSTP1 promotor than premenopausal ladies as OR was 2.167. Besides patients with Grade III tumor were 3 times at risk of having methylated promotor region than patients with Grade II tumor as OR was 3.059.
In addition, the hormonal status of the tumor tissues showed also no statistical significant relation, however OR in Her2 positive cases was 2.4, denoting that cases with Her2 positivity were more than two times at risk of having methylation in GSTP1 promotor (Table 2).

In addition, there were significant relations between Grade II tumors and ER and PR positivity ( $\mathrm{p}=0.006)$ and $(\mathrm{p}=0.010)$ respectively (Table 3 ). Also, all BC biopsies of luminal B type were of Grade II, otherwise no significant relation between molecular type of $\mathrm{BC}$ and age, menopausal state, or stage of the tumor (Table 4).

\section{Discussion}

Glutathione S-transferase P1 (GSTP1) is a phase II metabolic enzyme which plays a crucial role in the

Table 4. Relation between Tumor Molecular Types and Some Parameters in the Patients Group "Group2" (n=35)

\begin{tabular}{|c|c|c|c|c|c|c|c|c|c|c|}
\hline & \multicolumn{8}{|c|}{ Molecular type } & \multirow[t]{3}{*}{ Test of sig. } & \multirow[t]{3}{*}{$\mathrm{p}$} \\
\hline & \multicolumn{2}{|c|}{$\begin{array}{l}\text { Triple negative } \\
\qquad(\mathrm{n}=4)\end{array}$} & \multicolumn{2}{|c|}{$\begin{array}{l}\text { Luminal A } \\
(\mathrm{n}=23)\end{array}$} & \multicolumn{2}{|c|}{$\begin{array}{l}\text { Luminal B } \\
\qquad(n=4)\end{array}$} & \multicolumn{2}{|c|}{$\begin{array}{l}\text { Her } 2 \text { enriched } \\
\qquad(\mathrm{n}=4)\end{array}$} & & \\
\hline & No. & $\%$ & No. & $\%$ & No. & $\%$ & No. & $\%$ & & \\
\hline \multicolumn{11}{|l|}{ Age (years) } \\
\hline$>50$ & 2 & 50 & 9 & 39.1 & 2 & 50 & 0 & 0 & $\chi^{2}==2.943$ & $\mathrm{MC}_{\mathrm{p}}=0.549$ \\
\hline$\geq 50$ & 2 & 50 & 14 & 60.9 & 2 & 50 & 4 & 100 & & \\
\hline $30-40$ & 1 & 25 & 3 & 13 & 0 & 0 & 0 & 0 & $\chi^{2}==4.197$ & $\mathrm{MC}_{\mathrm{p}}=0.652$ \\
\hline$>40-49$ & 1 & 25 & 6 & 26.1 & 2 & 50 & 0 & 0 & & \\
\hline$\geq 50$ & 2 & 50 & 14 & 60.9 & 2 & 50 & 4 & 100 & & \\
\hline Mean \pm SD & \multicolumn{2}{|c|}{$47.5 \pm 9.68$} & \multicolumn{2}{|c|}{$52.22 \pm 9.14$} & \multicolumn{2}{|c|}{$52.75 \pm 7.32$} & \multicolumn{2}{|c|}{$58.0 \pm 6.38$} & $\mathrm{~F}=0.959$ & 0.424 \\
\hline \multicolumn{11}{|l|}{ Menstrual history } \\
\hline Premenopausal & 2 & 50 & 12 & 52.2 & 2 & 50 & 0 & 0 & \multirow[t]{2}{*}{$\chi^{2}==3.776$} & \multirow[t]{2}{*}{$\mathrm{MC}_{\mathrm{p}}=0.327$} \\
\hline Postmenopausal & 2 & 50 & 11 & 47.8 & 2 & 50 & 4 & 100 & & \\
\hline \multicolumn{11}{|l|}{ Grade } \\
\hline II & 2 & 50 & 22 & 95.7 & 4 & 100 & 2 & 50 & \multirow[t]{2}{*}{$\chi^{2}=8.990^{*}$} & \multirow[t]{2}{*}{$\mathrm{MC}_{\mathrm{p}}=0.017^{*}$} \\
\hline III & 2 & 50 & 1 & 4.3 & 0 & 0 & 2 & 50 & & \\
\hline \multicolumn{11}{|l|}{ Stage } \\
\hline Early stage & 3 & 75 & 14 & 60.9 & 1 & 25 & 2 & 50 & \multirow[t]{2}{*}{$\chi^{2}=2.415$} & \multirow[t]{2}{*}{$\mathrm{MC}_{\mathrm{p}}=0.647$} \\
\hline Late stage & 1 & 25 & 9 & 39.1 & 3 & 75 & 2 & 50 & & \\
\hline
\end{tabular}




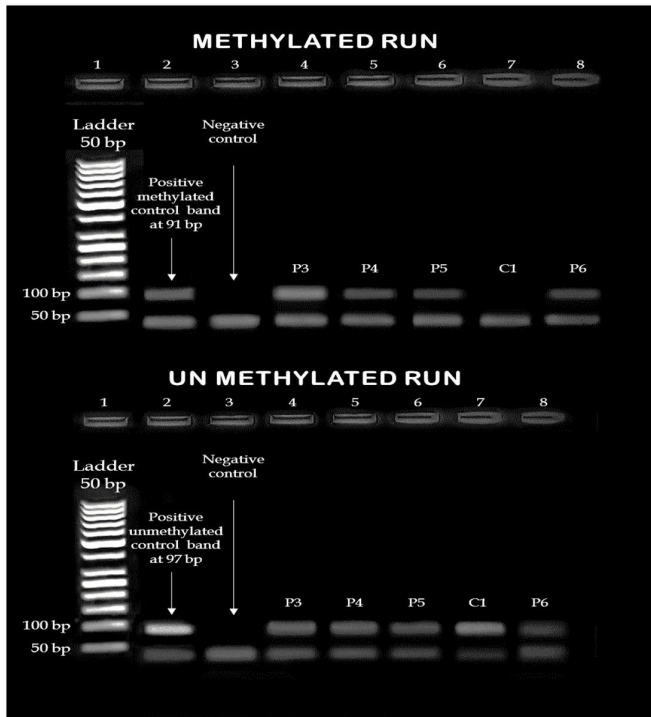

Figure 1. Methylated and Unmethylated bands in GSTP1 Promoter Gene Methylated GSTP1 Showed Bands at (91bp) and Unmethylated GSTP1 Showed Bands at (97bp).

detoxification process through biotransformation of exogenous substances, including mutagens and other carcinogens as conjugation of estrogen as part of its detoxifation (Raftogianis et al., 2000; Wu et al., 2012; Schnekenburger et al., 2014; Wu et al., 2016).

The GSTP1 which is expressed normally in breast epithelial cells and can be epigenetically inactivated in breast cancer (Byler et al., 2014), where its promotor hypermethylation was suggested to be one of its downregulation mechanisms found in many cancers (Otani et al., 2014).

The present work aimed at studying of the methylation status of the promotor region of glutathione-S-transferase $\mathrm{P} 1$ in breast ductal carcinoma in a cohort group of Egyptian females with breast cancer. The presence of methylation in GSTP1 promotor region was also correlated with the histopathological and prognostic parameters.

The results revealed significant increase in frequency of methylation $(\mathrm{p} \leq 0.001)$, in $\mathrm{BC}$ biopsies than that in the normal control biopsies. The big Odd's ratio $\{(\mathrm{OR})=21.0$, $95 \%$ confidence interval $(\mathrm{CI})=2.474-178.220\}$ denoted that the odds of finding the GSTP1 promotor region methylated in breast cancer tissues is 21 times the odds of finding normal control tissues methylated. The extended confidence interval could be attributed to small patients number.

In accordance with our study, Wu et al., (2016) and Bhat et al., (2017) found that significantly high frequency of the promotor methylation of GSTP1 gene in breast cancer cases $(\mathrm{p} \leq 0.001)$ when compared to the promotor hypermethylation profile of the normal tissues, and significantly hypermethylation of GSTP1 promotor region in breast cancer $(\mathrm{BC})$ as compared with Begnin Breast Disease (BBD) and controls $(\mathrm{p}=0.010$. Similar findings were reported by Fang et al., (2015) meta-analysis. However, similar patterns of methylation were found in benign breast lesions, as fibroadenomas as concluded by Cowin et al., (2005) .
The normal breast tissue showed very low percent of GSTP1 promotor methylation (6.7\%). This may prove the physiological role of GSTP1 as tumor suppressor gene which may prove its role as anti-toxic and anti-carcinogenic because GSTP1 is also known to be phase II metabolic enzyme (Lo et al., 2008) GSTP1 is capable of inhibiting tumor growth by interacting with the c-Jun N-terminal kinase (JNK1) signaling pathway (Wu et al., 2012; Schnekenburger et al., 2014), thus loss of its function may promote tumor growth. The increased methylation in this promotor region in the cancerous tissues leads to decrease of GSTP1 detoxification activity, hence accumulation of ROS, RNS, toxins and carcinogenic compounds which all lead to occurrence of cancer (Raza, 2011; Wu et al., 2012; Schnekenburger et al., 2014; Nissar et al., 2017). The silencing of GSTP1 due to promotor methylation found in many cancers where it is known as a tumor suppressor gene (TSGs) leads to lack of expression of GSTP1 which may prompt carcinogenesis and progression of breast cancer through accumulation of ROS, toxic and carcinogenic compounds (Brooks et al., 2009; Wu et al., 2016; Sheng et al., 2017).

The relation between GSTP1 methylation and gene expression was shown in several studies as Bhat et al., (2017) stated that epigenetic silencing of the GSTP1 gene by $\mathrm{CpG}$ promotor hypermethylation is associated with the significant loss of the protein expression. This conclusion was also consistent with Fang et al., (2015) who clarified in their meta-analysis that GSTP1 gene promotor hypemethylation occurs more in breast cancer and thus may lead to cancer progression through inactivation of GSTP1 expression. We found that there was no significant difference in the frequency of GSTP1 promotor methylation between pre and postmenopausal cases $(p=0.317)$. However, the OR was 2.167 which denoted that postmenopausal ladies were twice at risk to have methylated GSTP1 promotor than premenopausal cases. Saxena et al., (2012), Miyake et al., (2013), Wu et al., (2016) and Bhat et al., (2017) found similar results. The current work also found that there was no statistical significant difference in methylation status between nullipara and multipara patients.

No association was found between methylation status of GSTP1 promotor region and any of clinicopathological findings specially poor prognostic factors grade and Her2 positive tumors) same results were reported by Callahan et al., (2016). Also Lasabova et al., (2010) and Wu et al., (2016) found no association between methylation status of the promotor region GSTP1 and tumor size. On the other hand Myake et al., (2013) found that methylation status was related to larger tumor more than smaller tumor thus leading to worse prognosis $(\mathrm{p}=0.044)$. This difference could be explained by larger sample size included in the other study.

No statistical significant association between lymph node metastasis and GSTP1 methylation status was present in our study. The same was reported by Miyake et al., (2013), Otani et al., (2014), Callahan et al., (2016) and WU et al., (2016) as they found $88.8 \%, 64.9 \%$ and $100 \%$ of $\mathrm{LN}$ positive cases were unmethylated; respectively. On the contrary, Bhat et 
al., (2017) found that most of patients with methylated GSTP1 promotor region tumors had positive lymph node metastasis ( $\mathrm{p}=<0.001)$. Also, Lasabova et al., (2010) study showed a significant association between GSTP1 promotor region hypermethylation and lymph node metastasis $(p=0.0142)$. This difference with our result could be attributed to different sample sizes.

The present study also revealed that Grade III tumor patients are 3 times at risk of having methylated GSTP1 promotor region than Grade II tumor patients as the OR was 3.059 . Also $80 \%$ of Grade III tumor patients had methylated promotor region of GSTP1 while only $43.3 \%$ of Grade II tumor had unmethylated GSTP 1 promotor. But the methylation status of the GSTP1 promotor was not statistically associated with histological grade. This result comes with findings of Callahan et al., (2016). However Bhat et al., (2017) found a correlation between GSTP1 increased methylation and histological grade and Fang et al., meta-analysis (2015) showed that the level of GSTP1 methylation increased significantly with the increase of tumor grades compared to low grade breast carcinomas. Small sample size and different research design may explain this difference.

No statistical significance association was found between GSTP1 gene methylation status and tumor staging. This also came with Callahan et al., (2016) and WU et al., (2016). On the contrary, many studies concluded that there was statistical association between GSTP1 gene methylation and tumor stage as Fang et al., (2015) who found that level of GSTP1 methylation increased significantly $(p=0.039)$ in late-stage compared to the early stage breast carcinomas. They suggested that breast cancer patients with GSTP1 promotor hypermethylation may have a phenotype with more biological aggressiveness. The same observation was reported by Saxena et al., (2012) and Bhat et al., (2017) who showed significantly higher quantitative methylation levels in late stage compared to the early stage breast carcinoma $(\mathrm{p}=0.014, \mathrm{p}=0.03$; respectively). In addition Klajic et al., (2013) reported significant differences in methylation levels between the DCIS (Ductal carcinoma in situ) and invasive stage II tumors. They suggested the role of GSTP1 promotor methylation in cancer progression. In their study, different methodologies have been used for assessment of GSTP1 promotor region methylation status, as they used quantitative DNA analysis for methylation by pyro sequencing which had a higher sensitivity in detection of methylation.

Regarding hormonal status and its association with GSTP1 promotor methylation, $87.5 \%$ of ER negative patients had methylated promotor region of GSTP1, while $88.9 \%$ of PR negative had methylated GSTP 1 promotor region and $75 \%$ of Her 2 positive patients had methylation in promotor region of GSTP1 cases. All showed no statistical significant association between these hormonal receptor profile and methylation status of this promotor. These results were similar to Saxena et al., (2012) and Callahan et al., (2016) who reported also no significance association between methylation status and hormonal receptor status.

However, Bhat et al., (2017) revealed that there was positive association of the higher GSTP1 promotor methylation with the $\mathrm{PR}$ negative tumor $(\mathrm{OR}=3.33,95 \%$ confidence interval $(\mathrm{CI})=0.10-11.12, \mathrm{p}=0.046)$ and ER negative tumors $(\mathrm{OR}=4.86,95 \%, \mathrm{CI}=1.31-18.05$, $\mathrm{p}=0.018)$ when compared to the PR positive and ER positive tumors, respectively. Wu et al., (2016) also found that there was increase in promotor region methylation in ER negative and PR negative tumor but revealed no statistical significance. This may be explained by inhibition of GSTP1 gene expression which can add to the decrease of its capability to detoxify estrogen due to GSTP1 promotor methylation (Callahan et al., 2016).

On the other hand Kljac et al., (2013) reported that significant increase of GSTP1 level of methylation specifically in association with ER positive versus ER negative tumors. However they observed no significant association with PR status nor Her2 positive tumors.

In the present study, the clinicopathological risk factors of breast cancer namely menopause $(\mathrm{OR}=2.167)$, nullipara $(\mathrm{OR}=1.0)$, tumor grade $(\mathrm{OR}=3.059)$, stage $(\mathrm{OR}=1.0)$ and Her2 $(\mathrm{OR}=2.4)$ that showed Odd's Ratio of one or more in Egyptian females were associated with increase risk of methylation of GSTP1 promotor region. In addition, $75 \%$ of cases with HER 2 positive showed methylation in GSTP1 promotor region.

The current work, also reported that all cases with Her2 enriched tumors had methylated GSTP1 promotor region and $75 \%$ of cases with triple negative tumors had methylated GSTP1 promotor region. But $52.2 \%$ of cases with Luminal A tumors and $50 \%$ of cases with Luminal B tumors had methylated GSTP1 promotor region. This led to non significance statistical association between the BC molecular types and GSTP1 promotor hypermethylation.

On the contrary, Miyaki et al., (2012) found that luminal A, luminal B and HER2- enriched tumors were more likely to harbor GSTP1 promotor hypermethylation than basal-like tumors, suggesting that GSTP1 promotor hypermethylation might might have more important role in the pathogenesis of luminal A, luminal B and HER2-enriched tumors than basal-like tumors.

Holm et al., (2010) also reported that GSTP1 methylation levels in BC tumors were highly elevated in luminal-B and moderately elevated in luminal-A subtypes. Miyaki et al., (2013) reported that GSTP1 hypermethylated tumors with ER positivity were observed more frequently in luminal-B than luminal-A subtypes. This was not conformed in our work due to small sample data set.

In conclusion, since our results revealed the significant hypermethylation in GSTP1 promotor in BC tissues than that in normal tissues, this may suggest the possible role of GSTP 1 promotor hypermethylation in the pathogenesis of BC in Egyptian females. The absence of significant association of GSTP1 promotor methylation and the clinicopathological findings (menstrual status, parity, tumor size, grade or stage, lymph node metastasis, hormonal receptor profile [ER, PR and Her2] and molecular types) may prove its poor prognostic value.

\section{Acknowledgements}

All authors have contributed significantly to this work. 
The study was a part of an approved thesis and was not funded by any scientific body. The study was carried according to the declaration of Helsinki and approved by the ethical committee of our Institution.

\section{Conflicts of interest}

All authors declare that there's no conflict of interest is declared.

\section{References}

Allocati N, Masulli M, Di Ilio C, Federici L (2018). Glutathione transferases: substrates, inihibitors and pro-drugs in cancer and neurodegenerative diseases. Oncogenesis, 7, 1-8.

Alnaes GI, Ronneberg JA, Kristensen VN, Tost J (2015). Heterogeneous DNA methylation patterns in the GSTP1 promotor lead to discordant results between assay technologies and impede its implementation as epigenetic biomarkers in breast cancer. Genes (Basel), 6, 878-900.

Bhat A, Masood A, Wani K, et al (2017). Promotor methylation and gene polymorphism are two independent events in regulation of GSTP1 gene expression. Tumor Biol, 39, 1010428317697563.

Bray F, Ferlay J, Soerjomataram I, et al (2018). Global cancer statistics 2018: GLOBOCAN estimates of incidence and mortality worldwide for 36 cancers in 185 countries. $C A$ Cancer J Clin, 68, 394-424.

Brooks J, Cairns P, Zeleniuch-Jacquotte A (2009). Promotor methylation and the detection of breast cancer. Cancer Causes Control, 20, 1539-50.

Byler S, Goldgar S, Heerboth S, et al (2014). Genetic and epigenetic aspects of breast cancer progression and therapy. Anticancer Res, 34, 1071-7.

Callahan CL, Wang Y, Marian C, et al (2016). DNA methylation and breast tumor clinicopathological features: The Western New York Exposures and Breast Cancer (WEB) study. Epigenetics, 11, 643-52.

Cowin P, Rowlands TM, Hatsell SJ (2005). Cadherins and catenins in breast cancer. Curr Opin Cell Biol, 17, 499-508.

Desjardins P, Conklin D (2010). NanoDrop microvolume quantitation of nucleic acids. $J$ Vis Exp, 45, 2565.

Fang C, Wei XM, Zeng XT, et al (2015). Aberrant GSTP1 promotor methylation is associated with increased risk and advanced stage of breast cancer: a meta-analysis of 19 case-control studies. BMC Cancer, 15, 920.

Fazzari MJ, Greally JM (2004). Epigenomics: beyond CpG islands. Nat Rev Genet, 5, 446-55.

Holm K, Hegardt C, Staaf J, et al (2010). Molecular subtypes of breast cancer are associated with characteristic DNA methylation patterns. Breast Cancer Res, 12, R36.

Holmes EE, Jung M, Meller S, et al (2014). Performance evaluation of kits for bisulfite-conversion of DNA from tissues, cell lines, FFPE tissues, aspirates, lavages, effusions, plasma, serum, and urine. PLoS One, 9, e93933.

Huang Z-H, Hu Y, Hua D, Wu Y-Y, Song M-X, Cheng Z-H (2011). Quantitative analysis of multiple methylated genes in plasma for the diagnosis and prognosis of hepatocellular carcinoma. Exp Mol Pathol, 91, 702-7.

Ibrahim AS, Khaled HM, Mikhail NN, Baraka H, Kamel H (2014). Cancer incidence in egypt: results of the national population-based cancer registry program. $J$ Cancer Epidemiol, 2014, 437971.

Jin B, Li Y, Robertson KD (2011). DNA methylation: superior or subordinate in the epigenetic hierarchy?. Genes Cancer, 2, 607-17.

Kalmár A, Péterfia B, Wichmann B, et al (2015). Comparison of automated and manual DNA isolation methods for DNA methylation analysis of biopsy, fresh frozen, and formalin-fixed, paraffin-embedded colorectal cancer samples. J Lab Autom, 20, 642-51.

Karius T, Schnekenburger M, Ghelfi J, et al (2011). Reversible epigenetic fingerprint-mediated glutathione-S-transferase P1 gene silencing in human leukemia cell lines. Biochem Pharmacol, 81, 1329-42.

Klajic J, Fleischer T, Dejeux E, et al (2013). Quantitative DNA methylation analyses reveal stage dependent DNA methylation and association to clinico-pathological factors in breast tumors. BMC Cancer, 13, 456.

Lasabova Z, Tilandyova P, Kajo K, et al (2010). Hypermethylation of the GSTP1 promotor region in breast cancer is associated with prognostic clinicopathological parameters. Neoplasma, 57, 35-40.

Lo HW, Stephenson L, Cao X, et al (2008). Identification and functional characterization of the human glutathione S-transferase P1 gene as a novel transcriptional target of the p53 tumor suppressor gene. Mol Cancer Res, 6, 843-50.

Lo PK, Sukumar S (2008). Epigenomics and breast cancer. Pharmacogenomics, 9, 1879-902.

Miyake T, Nakayama T, Kagara N, et al (2013). Association of GSTP1 methylation with aggressive phenotype in ER-positive breast cancer. Anticancer Res, 33, 5617-23.

Miyake T, Nakayama T, Naoi Y, et al (2012). GSTP1 expression predicts poor pathological complete response to neoadjuvant chemotherapy in ER-negative breast cancer. Cancer Sci, 103, 913-20.

Nissar S, Sameer A, Rasool R, Chowdri N, Rashid F (2017). Glutathione S Transferases: biochemistry, polymorphism and role in colorectal carcinogenesis. J Carcinog Mutagen, $\mathbf{8}, 2-9$.

Otani Y, Miyake T, Kagara N, et al (2014). BRCA1 promotor methylation of normal breast epithelial cells as a possible precursor for BRCA1-methylated breast cancer. Cancer Sci, 105, 1369-76.

Onitilo AA, Engel JM, Greenlee RT, Mukesh BN (2009). Breast cancer subtypes based on ER/PR and Her2 expression: comparison of clinicopathologic features and survival. Clin Med Res, 7, 4-13.

Pongtheerat T, Pakdeethai S, Purisa W, Chariyalertsak S, Petmitr S (2011). Promotor methylation and genetic polymorphism of glutathione S-transferase $P 1$ gene (GSTP1) in Thai breast- cancer patients. Asian Pac J Cancer Prev, 12, 2731-4.

Raftogianis R, Creveling C, Weinshilboum R, Weisz J (2000). Chapter 6: Estrogen metabolism by conjugation. JNCI Monographs, 27, 113-24.

Raza H (2011). Dual localization of glutathione S-transferase in the cytosol and mitochondria: implications in oxidative stress, toxicity and disease. Febs $J, \mathbf{2 7 8}, 4243-51$.

Sambrook J, Russell DW (2006). The condensed protocols from molecular cloning: a laboratory manual . Cold Spring Harbor Labortatory Pres NY, p 5.

Saxena A, Dhillon VS, Shahid M, et al (2012). GSTP1 methylation and polymorphism increase the risk of breast cancer and the effects of diet and lifestyle in breast cancer patients. Exp Ther Med, 4, 1097-103.

Schnekenburger M, Karius T, Diederich M (2014). Regulation of epigenetic traits of the glutathione S-transferase P1 gene: from detoxification toward cancer prevention and diagnosis. Front Pharmacol, 5, 170.

Sheng X, Guo Y, Lu Y (2017). Prognostic role of methylated GSTP1,p16, ESR1 and PITX2 in patients with breast cancer: A systematic meta-analysis under the guideline of PRISMA. Medicine (Baltimore), 96, e7476.

Wajed SA, Laird PW, DeMeester TR (2001). DNA methylation: 
an alternative pathway to cancer. Ann Surg, 234, 10-20.

Wu B, Dong D (2012). Human cytosolic glutathione transferases: structure, function, and drug discovery. Trends Pharmacol Sci, 33, 656-68.

Wu L, Shen Y, Peng X, et al (2016). Aberrant promotor methylation of cancer-related genes in human breast cancer. Oncol Lett, 12, 5145-55.

Yang M, Park JY (2012). DNA methylation in promotor region as biomarkers in prostate cancer. Methods Mol Biol, 863, 67-109.

This work is licensed under a Creative Commons AttributionNon Commercial 4.0 International License. 